\title{
Human and Cobot Cooperation Ethics: The Process Management Concept of the Production Workplace
}

\section{- Felicita Chromjakova, Damien Trentesaux, Michael Adu Kwarteng}

\begin{abstract}
The competitiveness of modern companies depends today on the ability to implement digitised technologies into production processes in human-friendly ways. The aim of this paper is to analyse ethical aspects of human-cobot cooperation in industrial production and to design a process standard aimed at ensuring an ethically stable cooperative workplace. The scientific contribution of this study lies in the identification and definition of standardized parameters of the ethics of the production process in the workplace. Based on the analysis of cooperative workplaces in 250 industrial companies, a code of ethics has been defined, i.e. a process standard that determines the navigation of the design by selected optimization criteria necessary for setting up a hybrid workplace defined as human and cobot (collaborative robot) with the support of digitised technologies. In the presented results and the final discussion attention is devoted to the need to radically change the philosophy of workplace standardization in the sense of equal access to workload settings by humans and robots. In the process of standardization, it is necessary to consider the difference in the standardization of human jobs and cobot jobs: the thinking process. In modern industrial companies the need has arisen to create working standards that take into account the adaptive ability of cobots and adapt the cobots' workflow to human needs concerning performance and productivity. The presented results include recommendations for industrial companies to develop an ethical and stable production workplace based on an adequately defined form of cooperation.
\end{abstract}

Keywords: process, ethics, workplace, productivity, buman-machine cooperation JEL Classification: L25, L60, L84

Received: September, 2020

1st Revision: March, 2021

Accepted: August, 2021

\section{INTRODUCTION}

Today industrial companies are confronted with the gradual onset of digitised processes to improve their competitiveness. Human-cobot collaboration is based on machine learning and human learning-based strategies (Al Yacoub et al., 2021). In creating ethical standards for the workplace, it is important to focus on harmonizing stochastic human behaviour and the adaptive process algorithm of cobots (Cheng et al., 2021). Industrial companies are today faced with 
the requirement of instituting digitised processes, which will radically increase the demands for ethical process standardization (Zhao \& Oh, 2020). Directly related to this is the question of how to design, organize, and manage workplaces where human-robot cooperation takes place. Corporate IT and production system architects are examining workplaces, especially in terms of the many types of human activities, with a lower quality of productivity and final performance often being shown. In this context, it is essential to investigate the potential risks of cobot and human job conflict at the workplace. Human consciousness has been shown to identify with certainty that a cobot will do its job correctly by the established rules (Fisher et al., 2020). Still, two possible types of collision may occur between humans and cobots: technological and ethical (Chromjaková, 2018). Fostered by the increasing technological offer of digitalization, the impact of ethics in the search for improved competitiveness is well worth studying (Shleifer, 2004). At first glance, ethics in this context concerns the business level. Still, ethical issues may also concern a more operational level, which is the topic of this paper. At this level the behaviour of operators and their interactions with other operators, machines, and technical elements can be characterized in terms relevant to ethics, such as fairness, helpfulness, empathy, and kindness. It has been shown that hypercompetitive people tend to be highly Machiavellian but not as ethically idealistic (Mudrack et al., 2012). The basic question for industrial engineers is, therefore, how to resolve issues of mutual communication and cooperation between humans and cobots, a theme which involves a special ethical level connected with optimal performance, human, and process satisfaction. For example, the production worker uses his/her knowledge and experience to set up a work standard and is primarily responsible for standardized workplace performance. In turn, performance improvement is perceived as strongly influenced by "workplace spirituality" and "meaningful work" (Yoo \& Glardon, 2020). Our initial scientific analysis necessary for establishing a human and cobot cooperation ethics process and management concept of production workplace was focused on the identification of the following assumptions:

- Mutual human-cobot cooperation in the production workplace is directly dependent on an adequate level of standardized processes.

- The production planner can identify crucial parameters of ethical human-cobot cooperation at the workplace.

- The standardized workplace has defined optimal ethical conditions for realizing planned production performance in the form of a human-cobot workforce.

- The compliance assessment follows the same rules for both the human and cobot concerning jobs done in the workplace.

- In the field of standardization of workplace operations and workplaces, we distinguished between traditional human waste and digitally controlled cobot waste (e-waste).

- All core human and cobot responsibilities are identified and used for standardized processes by the workplace organizations.

In section two, the theoretical background of this paper is discussed based on the most recent publications on the topic. Section three contains the research objective and our contribution, which consists of a methodological approach dedicated to analysis process standardization 
in human-cobot workplaces considering ethical aspects. In the fourth section, the results are presented, followed by a discussion and conclusions.

\section{THEORETICAL BACKGROUND}

Industrial companies are currently investing considerable resources and effort in the process of human-cobot interaction (Zaatari et al., 2019) with an emphasis on standardized procedures in the workplace. The design of mutual interactions, flexible production planning, and organization realized with the help of machine sensors are crucial for digitized production layouts. With the institution of human-cobot cooperation, a new level of ethical behaviour is introduced in the workplace. Many authors point to the need for the proper regulation of production size, assembly processes, organization, process, and life cycle optimization. Cobots are a systematic technology dedicated to the elimination of human assembly tasks. Component sizes and required product tolerances have a strong influence on human productivity, especially in regards to time, when the assembly tasks require a high level of customization (Salmi et al., 2008). Integration of computing with a company's culture leads to discussions regarding ethical consequences. A multidimensional and interdisciplinary orientation have become the core attributes of the digitised workplace in processes (Brahma, 2019) that will only expand in the future, with new roles emerging connected to knowledge and skills from realized production operations (Sharma et al., 2018). In this context, the concept of Operator 4.0 has been suggested (Romero et al., 2020). This concept is based on the idea that the skilled operator is able to perform the tasks in a targeted and standardized form. Therefore, he is able to cooperate in the form of "work system symbiosis" (Pacaux-Lemoine, 2019). Ethics comes into this process, e.g. regarding the goals and boundaries of the workplace designer. The requirement of a smooth process is in this case connected with the capabilities of both humans and cobots. The moral site of this problem depends on experiences in various working situations (Kopacek, 2018). The implementation of cyber-physical systems in factory life has preconditioned the structure and content of information and material flow as a basic parameter of digitised production systems (Cardin, 2019). In the literature, we can find a number of comments on the new structure of such industrial production systems oriented to more effective human-cobot collaboration. Applied in the workplace as a part of complex production performance, cobots are physically segregated from humans, which means that during the realization of production performance, the human assists the cobot in performance realization. In observations of the manufacturing system, we can see in reality how humans "communicate" with cobots and supplementary cobot devices. Humans must devote attention not only to this process, but also to their own cooperation with cobots. Therefore, the ethical side of this process organization is an important component of performance monitoring and evaluation (Fletcher, 2017). In the whole spectrum of industrial companies, we strive for smart factory solutions and workplace applications that have the task of replacing routine human activities through intelligent machines.

The basis of this process is the use of programmable sensors, cloud technology concepts, machine learning algorithms for working procedures, and information flow management. Cobots and robots are new team members, i.e. new employees, whose responsibility for the process 
is described by specified employment laws (Wildhaber, 2018). The core equivalence principle states that if it would be wrong to subject or allow individuals to have a particular experience in reality, then that experience in a virtual reality setting is also wrong (Ramirez \& LaBarge, 2018). Closer attention will be directed towards the area of human learning at the workplace (Sanda, 2020), which is a crucial change in this digitised production era in which ethical comfort is strongly influenced by new personnel skills (Dornberger, 2018). Cobots have the competency to manage humans in the production process, helping them with process constraints in the case of standardized procedures, but they cannot replace humans in cooperative jobs; they can only give programmable recommendations. The ethics of human-cobot cooperation, in this case, have been addressed by the regulation of programmable instructions which can direct the process flow in the desired direction (Bendel, 2018). Human workplace safety must also be measured in the production process. This reality is potentially critical in a scenario in which more autonomous and intelligent machines have come to replace routine tasks, with productivity and efficiency becoming tasks for robots and machines (Espada \& Rosa, 2018). While the technological advances have been remarkable and rapid, the social and ethical implications of these new systems have been largely ignored (Trentesaux \& Karnouskos, 2019). Only during the past decade have we seen the emergence of the field of "cobot ethics" (Lin et al., 2012). Collaborative robots and humans share the same workplace, which means morality and ethical status raise the requirements for stable job definitions and standardization.

Risk management, connected with process flow, is an important tool in how the production planner and designer influence production flow. As we add cobots as humans' co-workers, we have to define the tasks and competencies connected with the optimized workplace (Jocelyn et al., 2017). The development of new technologies in the area of artificial intelligence brings a lot of digitised access to the area of human-cobot process standardization (Simoes et al., 2020). This type of technological development is strongly connected with the ethical site of humans and the interconnectivity of cobots (Doyle \& Senske, 2018). In the mentioned concept, the human works as a system component that owns their own identity, competencies, and responsibilities for a process. Importantly, such a defined system component has a centralised position in the production system (Steusloff, 2016). Workplace ethics and ethical behaviour are connected with production process planning and organization (Didomenico, 2019). Here, we can speak about technical attributes such as trustworthiness, safety, and security, and social attributes such as altruism, accountability, or equitability (Trentesaux \& Karnouskos, 2019). We can also speak about the ethics of technique: human intelligence connected with artificial intelligence by cobots and how it relates to cyber-physical systems. Indeed, the integration of robotic systems is not neutral for human health and well-being, for example (Pollak et al., 2020). In today's factories, we can identify several ethical trends influencing standardized workplace organization:

- The cyber-physical system requires standardized job realization rules in the form of ethical standards for human-cobot cooperation, a complex knowledge system that continuously enables the achievement of specified ethical practices.

- Various components of the socio-technical system of the workplace are in conflict; we have to find a relevant mutual balance between them, as one component can degrade another.

- Ethical workplaces can be characterized by the possibility of action choice, meaning that the 
human or cobot should be able to find a "win-win" situation or have a direct comment for action in the case of "no-win" decisions.

- A flexible production system in digitized technology is connected with ethicality in the whole production chain. When we stabilize core processes, we have a relatively high chance of measuring the ethical status of a process realized by the workplace, i.e. we can use past relevant process knowledge and skills.

- The cyber-physical system as a methodological tool for human-cobot cooperation assumes the relevant description of workplace coordination rules. An important factor - the ethical workplace - evokes an adequate definition of all work tasks realized by the workplace and optimal definition and standardization of digitised rules.

A machine can do the planned job through the given instructions. It is also able to do repetitive tasks in a predictable environment. Knowledge is definitely something we need to pursue, and knowledge needs to go beyond understanding the introduced technology. Strengths and weaknesses are resistant to change. An analysis of the workplace reveals ethical questions that require the attention of managers, owners, and trustees. Typically, the workplace situations for the jobs done are connected with relevant human and technical qualifications, which are important assumptions for tasks carried out during the production process. Bio design refers to living matter as a technology when living organisms are essential components of the technology (Vettier, 2019). Relevant job descriptions by the workplace mean that the human has defined the required job steps, metrics for performance evaluation, motivation factors for process improvements, and relevant mutual connections with other humans or cobots. Similarly, when we need to evaluate, plan, and organize future workplace activities, we must identify specific problem areas that occurred in past processes. Continuous improvement processes have the potential to take adequate actions oriented to the improvement of digitally managed material and information flows. Next, they contribute to human qualification improvement and cobot activities statement according to the process performance and efficiency.

The attribute of specialized people invitation plays an important role here: it is necessary to know all the relevant process risks that influence the ethical site of the production process. If we know the opinions of specialists, we can identify potential risks earlier and without potential losses (Didomenico, 2019). Digitised production technology brings new ways of thinking about materials and tools used in production workplaces according to job processing (Brennan, 2018). During the last year, we can see that humans are increasingly confronted with a new type of cooperation: mainly, employees have to learn new technologies, they have their first practical experience with those technologies, and then they finally can work with new types of automated and digitized tools. In the case of technical conflicts, they have the possibility of communicating and resolving the situation with the responsible people. Then process realization is flexible and optimal. In many industrial companies, as automation and digitization grow, the number of connected workplaces in digitised processes becomes more complex, and the requirement on skilled personnel is crucial. Today's production processes in many companies show signs of sophisticated automation and digitization, which is directly connected with cost management at the workplace. The dominant factor there is the real availability of digitised technology for production performance. According to the production costs per unit, we strive to manage the 
level of variable costs and manage, on a strategical level, the fixed cost - both parameters are oriented to the reduction of cost per hour (Yoo, 2018).

\section{RESEARCH OBJECTIVE, METHODOLOGY AND DATA}

The research objective of this paper was to analyse the crucial assumptions of effective humancobot cooperation and, based on this analysis, to define the catalogue of prerequisites and workplace process standards for the ethical human-cobot workplace. The logic of the research activities was focused on production workplace ethics with the goal of achieving a stable level of workplace ethics. This should contain human satisfaction with realized job output by the workplace. Firstly, we identified the appropriate parameters for workplace ethics as core pillars of methodology and research orientation for individual interviews (Figure 1).

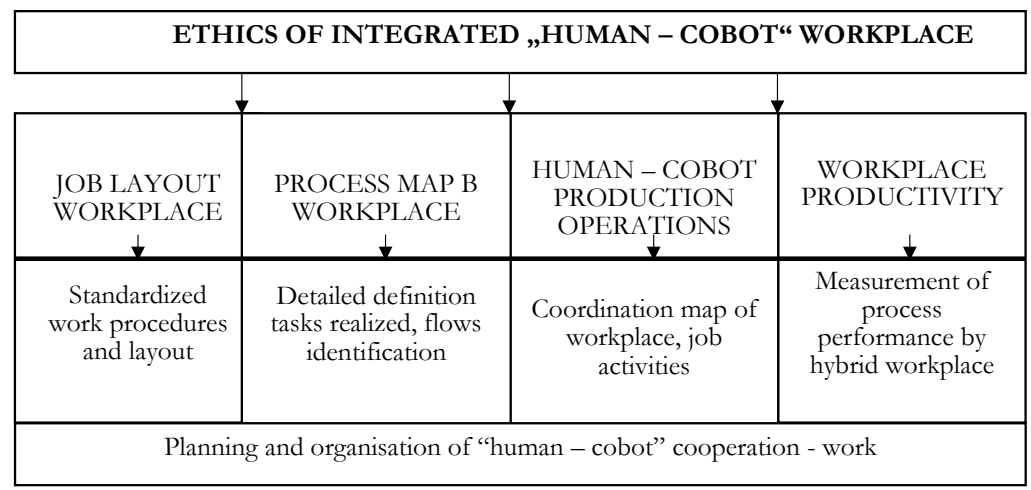

Fig. 1 - The proposed research methodology. Source: own research

The basis of the data analysis was a focus on a systemic understanding of the human-cobot relationship. The results of the analysis were used for the definition of selected parameters of work optimization at the hybrid workplace. Production workplace standardization, given by the production plan and realized by the layout of human-cobot workplaces, evokes the relevant scheduling of process task realization according to the abilities of the human or cobot. These influence the real-time schedule, dedicated primarily to cobot tact time (Goleman, 2000).

Research questions were elaborated and oriented to systematic individual interviews with production managers in 120 industrial companies (50\% international and 50\% national companies). Descriptive statistics and arithmetic mean were used for the evaluation of the results.

The goal of this stage was to identify the main human-cobot dependencies as core assumptions for human-cobot process standardization, with a focus on the role of ethics in the production workplaces (Table 1). The introduced typology describing the various dimensions of ethics was used. 
Tab. 1 - Human-cobot workplaces ethical cooperation analysis. Source: own research

\begin{tabular}{|c|c|c|c|c|c|}
\hline \multicolumn{6}{|c|}{$\begin{array}{l}\text { HUMAN-COBOT WORKPLACE ETHICAL COOPERATION AND COMMUNICATION - RE- } \\
\text { SEARCH OF KEY ASSUMPTIONS OF ETHICAL COOPERATION(120 automotive companies } \\
\text { CZ+SK) }\end{array}$} \\
\hline $\begin{array}{l}\text { Workplace at- } \\
\text { tribute toward } \\
\text { ethics }\end{array}$ & $\begin{array}{l}\text { Assumptions } \\
\text { of ethical } \\
\text { cooperation by } \\
\text { workplace }\end{array}$ & $\begin{array}{l}\text { Number of used } \\
\text { HUMAN ethi- } \\
\text { cal standards }\end{array}$ & $\begin{array}{l}\text { Number of used } \\
\text { COBOT ethical } \\
\text { standards }\end{array}$ & $\begin{array}{l}\text { Standards of } \\
\text { ethics used }\end{array}$ & $\begin{array}{l}\text { Behaviour } \\
\text { standards } \\
\text { used }\end{array}$ \\
\hline \multirow[t]{3}{*}{ Cooperation } & Credibility & $\begin{array}{l}85 \text { SMEs } \\
12 \text { SMEs next } \\
\text { months } \\
23 \text { - in future }\end{array}$ & $\begin{array}{l}98-\text { full } \\
22-\text { SMEs next } \\
\text { months }\end{array}$ & 76 SMEs have it & 46 SMEs \\
\hline & Mental comfort & $\begin{array}{l}113 \text { - full } \\
7 \text {-SMEs next } \\
\text { months }\end{array}$ & $\begin{array}{l}95 \text { - full } \\
25 \text { - SMEs next } \\
\text { months }\end{array}$ & 64 SMEs have it & 92 SMEs \\
\hline & Stability & $\begin{array}{l}87-\text { full } \\
33 \text { - SMEs next } \\
\text { months }\end{array}$ & $\begin{array}{l}89-\text { full } \\
12-\text { SMEs next } \\
\text { months } \\
19-\text { in future }\end{array}$ & $\begin{array}{l}112 \text { SMEs } \\
\text { have it }\end{array}$ & 75 SMEs \\
\hline \multirow[t]{4}{*}{ Communication } & Altruism & $\begin{array}{l}23-\text { full } \\
4-\text { SMEs next } \\
\text { months } \\
93-\text { in future }\end{array}$ & $\begin{array}{l}56-\text { full } \\
36-\text { SMEs next } \\
\text { months } \\
84-\text { in future }\end{array}$ & $\begin{array}{l}118 \text { SMEs } \\
\text { have it }\end{array}$ & 24 SMEs \\
\hline & Responsibility & $\begin{array}{l}85-\text { full } \\
12-\text { SMEs next } \\
\text { months } \\
23-\text { in future }\end{array}$ & $\begin{array}{l}98-\text { full } \\
22-\text { SMEs next } \\
\text { months }\end{array}$ & 76 SMEs have it & 46 SMEs \\
\hline & Equality & $\begin{array}{l}23-\text { full } \\
4-\text { SMEs next } \\
\text { months } \\
93-\text { in future }\end{array}$ & $\begin{array}{l}56-\text { full } \\
36-\text { SMEs next } \\
\text { months } \\
84 \text { - in future }\end{array}$ & $\begin{array}{l}118 \text { SMEs } \\
\text { have it }\end{array}$ & 24 SMEs \\
\hline & SCORE & $\begin{array}{l}78 \text { SMEs prefer } \\
\text { organized ethi- } \\
\text { cal behaviour }\end{array}$ & $\begin{array}{l}112 \text { SMEs will } \\
\text { have ethical } \\
\text { cooperation } \\
\text { of maintainer } \\
\text { with cobot and } \\
\text { operator }\end{array}$ & & \\
\hline \multicolumn{2}{|c|}{$\begin{array}{l}\text { Selected parameters of "code } \\
\text { of ethics" by "human-cobot } \\
\text { workplace"(Source data in the } \\
\text { table: frequency of "yes/no" } \\
\text { answers by given attributes and } \\
\text { assumptions) }\end{array}$} & \multicolumn{4}{|c|}{$\begin{array}{l}117 \text { SMEs - big data-oriented on the ethical production process } 95 \\
\text { SMEs - human rules acceptance by hybrid workplaces (balanced } \\
\text { cooperation human - cobot) } 99 \text { SMEs - performance level accep- } \\
\text { tance by human } 120 \text { SMEs - production planning and scheduling of } \\
\text { digitised processes in cooperation with humans and with reflection } \\
\text { on their ethical needs }\end{array}$} \\
\hline
\end{tabular}




\section{RESULTS AND DISCUSSION}

The research was done during 2018-2019 in selected SMEs in the Czech and Slovak Republics. The tested industrial companies included four industrial areas: automotive, engineering, electrical, and chemical. The following structure of research questions was used (Table 2):

1. Ethical workplace process flow: What is the precise process operation flow managed by human-cobot ethical cooperation?

Tab. 2 - Ethical workplace process flow - conditions of ethical stability. Source: own research

\begin{tabular}{|l|l|l|l|l|}
\hline $\begin{array}{l}\text { CORE GROUP: SMEs Type of } \\
\text { process flow }\end{array}$ & $\begin{array}{l}\text { automotive } \\
\text { SMEs }\end{array}$ & $\begin{array}{l}\text { Engineering } \\
\text { SMEs }\end{array}$ & $\begin{array}{l}\text { Electrical } \\
\text { SMEs }\end{array}$ & $\begin{array}{l}\text { Chemical } \\
\text { SMEs }\end{array}$ \\
\hline $\begin{array}{l}\text { Digital managed and scheduled } \\
\text { workplace layout }\end{array}$ & 87 & 37 & 46 & 18 \\
\hline $\begin{array}{l}\text { Production job description for } \\
\text { "human - cobot" cooperation by } \\
\text { workplace }\end{array}$ & 92 & 42 & 47 & 23 \\
\hline $\begin{array}{l}\text { Human-cobot production } \\
\text { operations standardization }\end{array}$ & 94 & 47 & 46 & 28 \\
\hline $\begin{array}{l}\text { Workplace productivity } \\
\text { measurement }\end{array}$ & 111 & 50 & 50 & 30 \\
\hline $\begin{array}{l}\text { Number of SMEs in a relevant } \\
\text { category (column) }\end{array}$ & 120 & & 26 \\
\hline
\end{tabular}

* the number of SMEs in the given column

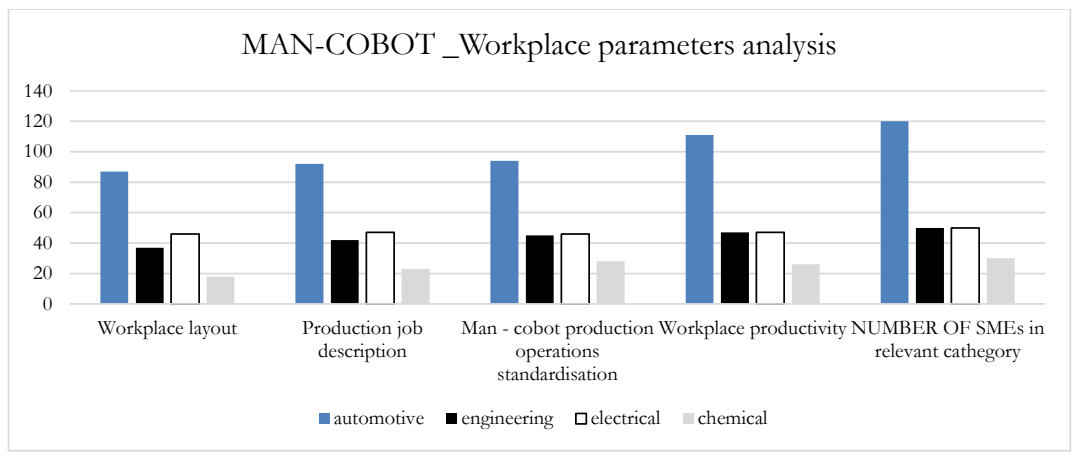

Fig. 2 - Graphical view on Man_Cobot workplace parameters analysis. Source: own research

2. Process task definition: Does the task definition done by the production workplace influence the productive ethics and effective cooperation between humans and cobots? (SMEs in total). This is primarily influenced by:

- Complex level of clear understanding of task done by humans and cobots: 247 companies

- Visualization of the job description by workplace: 137 companies 
- On-line time planning and tasks scheduling by workplace: 198 companies

- Order management by customer scheduling of production operations by workplace: 211 companies

- Minimization of process conflicts between human and cobot by workplace: 167 companies

3.Hybrid human-cobot collaboration: Does people's process activation influence the ethical organization of the standardized production layout (Table 3)?

Tab. 3 - Analysis of "human - cobot" hybrid cooperation. Source: own research

\begin{tabular}{|l|l|l|l|l|}
\hline $\begin{array}{l}\text { CORE GROUP: SMEs Activation } \\
\text { influence on the ethical organization }\end{array}$ & automotive & engineering & electrical & chemical \\
\hline $\begin{array}{l}\text { Digitised process flow layout connected } \\
\text { with online process management }\end{array}$ & 113 & 35 & 41 & 13 \\
\hline $\begin{array}{l}\text { Effective real-time scheduling of } \\
\text { process tasks }\end{array}$ & 97 & 42 & 45 & 23 \\
\hline $\begin{array}{l}\text { Roll-out on-line priority-oriented } \\
\text { production schedule }\end{array}$ & 99 & 37 & 28 & 11 \\
\hline $\begin{array}{l}\text { Process tasks done by customer-defined } \\
\text { tasks times }\end{array}$ & 67 & 41 & 39 & 27 \\
\hline $\begin{array}{l}\text { Code identification of done production } \\
\text { tasks }\end{array}$ & 98 & 23 & 35 & 25 \\
\hline $\begin{array}{l}\text { Support of production schedule by } \\
\text { cloud computing }\end{array}$ & 56 & 27 & 24 & 17 \\
\hline $\begin{array}{l}\text { Digitised monitoring of selected KPIs } \\
\text { by workplace }\end{array}$ & 120 & 50 & 50 & 30 \\
\hline Number of SMEs in a relevant category
\end{tabular}

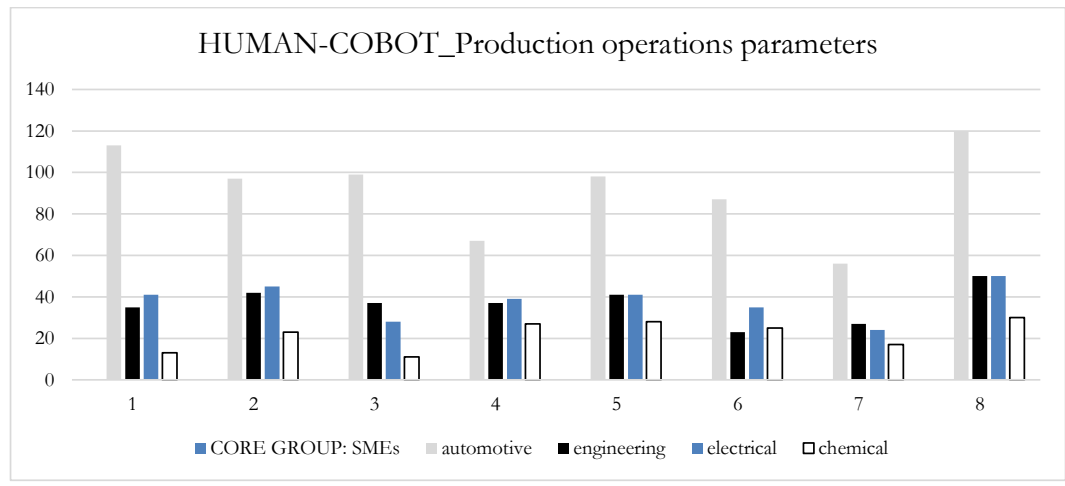

Fig. 3 - Graphical view on Human-Cobot production operations parameters. Source: own research 
3. The efficiency of tasks done: Does digitised process information flow influence the effective connectivity between human and cobot according to the digital literacy of the human? During individual interviews with production managers in selected industrial companies, it was important to consider the phenomena of emotion and empathy by process standardization. Feelings about reality are influenced mainly by the psychological overload of the human; 178 companies qualified it as an essential factor.

The cobot is able to recognize psychological moments, which occur in cooperation, and it responds through adequate reaction to the raised situation at workplace.

General types of empaths:

- A human tends to change behaviour according to physical body comfort and eliminate the load.

- A human who absorbs physical discomfort and reacts to the effect of the emotions they absorb.

- Emotional perception of a workplace situation - based on own skills, the human eliminates ethical conflicts by the workplace.

Problems in the production workplace can significantly influence mutual performance, so the impact on ethical comfort is crucial. The core problem is the strict definition of job layout by workplace: human and cobot are managed online by a digitised software platform. This type of process organization eliminates ethical uncertainty. According to the individual interviews, the following key performance indicators (KPIs) were constructed for workplace testing in the area of ethical cooperation between humans and cobots. Individual indicators were selected on the basis of the analysis concerning SMEs:

1. Availability of a continuous production flow by "human-cobot" workplace (ACPF) $\mathrm{ACPF}=\mathrm{ATP}-\mathrm{PST}-\mathrm{MP} \quad$ [minute]

(ATP - availability time planned, PST - planned service time, MP - maintenance prevention)

2. E-processed time of operation (lead time) (EPTO)

$\mathrm{EPTO}=\mathrm{SIT}+\mathrm{ECT}+\mathrm{SRT}+$ IPIS $\quad$ [minute $]$

(SIT - system instruction time, ECT - e-operation cycle time, SRT - system reaction time, IPIS - input process instruction for a system)

3. System incident reaction time (SIRT)

SIRT $=$ UTS - DIT - TEI [minute]

(UST - unavailability system time, DIT - diagnosed incident, TEI - time of incident elimination)

4. Data complexity index - digitized process (DCI) $\mathrm{DCI}=\mathrm{DSON} / \mathrm{TNDO}$

(DSON - digitized system operation number, TNDO - total number of digitised operations)

5. Human-cobot ethical cooperation factor (HCECF)

$\mathrm{HCECF}=\mathrm{F}_{\mathrm{plm}}+\mathrm{F}_{\mathrm{prlm}}+\mathrm{F}_{\mathrm{perlm}}$ 
(optimization criterion: $\operatorname{maxHCECF}=1,0$, higher value has potential for workplace innovation by human cobot ethical standards)

$\left(\mathrm{F}_{\mathrm{plm}}-\right.$ process level motivation, $\mathrm{F}_{\mathrm{prlm}}$ - product level motivation, $\mathrm{Fp}_{\mathrm{erlm}}$ - personality level motivation)

A rating scale was designed for HCECF parameter as follows (level of cooperation, given as \% of successfully done jobs by ethical human-cobot workplace):

$\mathrm{F}=0.5$ total volume of task completion by human-cobot workplace, full satisfaction without mutual conflict of task realization

$\mathrm{F}=0.4$ limited volume of tasks completion by human - cobot, it occurs the process conflicts with $\max 20 \%$ of tasks done by the workplace (or max $20 \%$ disruptions caused by system failure)

$\mathrm{F}=0.3$ medium volume of task completion by human - cobot, only $50 \%$ planned tasks were done (late process specification, absence of material, bad system instruction by cobot, etc.)

$\mathrm{F}=0.2$ minimal volume of task completion by human - cobot, only $20 \%$ operations planned by the workplace were done ( $80 \%$ process conflict)

Tables 4 and 5 contain the results of these calculations. Values in the tables are based on the internal audit of the hybrid workplace ( $\%$ of the fulfillment of standardized criteria).

Tab. 4 - Calculation of ACPF, EPTO and SIRT - example. Source: own research

\begin{tabular}{|l|l|l|l|l|l|l|l|l|l|l|l|l|}
\hline ATP & PST & MP & ACPF & SIT & ECT & SRT & IPIS & EPTO & UTS & DIT & TEI & SIRT \\
\hline 12 & 3 & 4 & 19 & 5 & 8 & 1 & 3 & 17 & 3 & 5 & 6 & -8 \\
\hline 12 & 0 & 1 & 13 & 5 & 8 & 1 & 3 & 17 & 0 & 0 & 0 & 0 \\
\hline 14 & 5 & 0 & 19 & 6 & 8 & 1 & 3 & 18 & 5 & 5 & 4 & -4 \\
\hline 14 & 5 & 3 & 22 & 5 & 8 & 1 & 3 & 17 & 5 & 2 & 1 & 2 \\
\hline 13 & 2 & 1 & 16 & 5 & 8 & 1 & 3 & 17 & 2 & 2 & 1 & -1 \\
\hline 12 & 3 & 4 & 19 & 5 & 8 & 1 & 3 & 17 & 3 & 1 & 1 & 1 \\
\hline 12 & 0 & 2 & 14 & 5 & 8 & 1 & 4 & 18 & 0 & 0 & 0 & 0 \\
\hline 13 & 5 & 1 & 19 & 7 & 8 & 2 & 3 & 20 & 5 & 3 & 2 & 0 \\
\hline 12 & 2 & 4 & 18 & 5 & 8 & 1 & 3 & 17 & 2 & 2 & 1 & -1 \\
\hline 12 & 2 & 4 & 18 & 5 & 8 & 1 & 3 & 17 & 2 & 2 & 1 & -1 \\
\hline
\end{tabular}

Tab. 5 - Calculation of DCI and HCECF - example. Source: own research

\begin{tabular}{|l|l|l|l|l|l|l|}
\hline DSON & TNDO & DCI & $F_{\text {plm }}$ & $F_{\text {prlm }}$ & $F_{\text {perlm }}$ & HCECF \\
\hline 6 & 4 & 1.50 & 0.20 & 0.50 & 0.30 & 1.00 \\
\hline 10 & 1 & 10.00 & 0.30 & 0.30 & 0.40 & 1.00 \\
\hline 8 & 2 & 4.00 & 0.30 & 0.40 & 0.30 & 1.00 \\
\hline 9 & 3 & 3.00 & 0.30 & 0.40 & 0.30 & 1.00 \\
\hline 10 & 1 & 10.00 & 0.30 & 0.20 & 0.40 & 0.90 \\
\hline 10 & 1 & 10.00 & 0.30 & 0.40 & 0.30 & 1.00 \\
\hline
\end{tabular}




\begin{tabular}{|l|l|l|l|l|l|l|}
\hline 9 & 1 & 9.00 & 0.30 & 0.30 & 0.30 & 0.90 \\
\hline 7 & 3 & 2.33 & 0.30 & 0.30 & 0.40 & 1.00 \\
\hline 10 & 1 & 10.00 & 0.30 & 0.30 & 0.40 & 1.00 \\
\hline 10 & 1 & 10.00 & 0.30 & 0.20 & 0.40 & 0.90 \\
\hline
\end{tabular}

In selected SMEs, a lot of discussions were realized on this topic. The ethical site of workplace standardization was explicitly discussed in strong connection with production layout planning and production scheduling. As a result, the catalogue of prerequisites for human-cobot workplace standardization was identified (Table 6).

Tab. 6 - Human-cobot workplace standard - a catalogue of assumptions. Source: own research

CORE PROCESS COMPONENTS INTEGRATED BY INDUSTRY 4.0 DESIGNED
WORKPLACE (a list of recommended assumptions)

Process system functionality availability supported by computerised and digitised technologies.

Availability of required services integrated cloud computing and big data systems.

Integrated IP and big data connections in Industry 4.0 concept.

Parametrical identification of technical, virtual communication and process measurement and the availability of an acceptable combination of human-cobot workplace performance levels.

System component structure and flexibility standardization.

System boundaries according to the process input/output conditions determined using econnections.

ID-chain. IP-addresses and ID administrator competencies and responsibilities, job content and structure.

Process flow of human-workplace conflict solutions (technical, technological, interface, cybersecurity, or others).

Number of production processes digitised for the process flow.

Number of total digitised production technologies (integrated human-cobot workplaces).

Performance-oriented human competition and responsibility in the Industry 4.0 chain.

Lead time before implementation of human-cobot workplace.

Lead time during the implementation of human-cobot workplace.

Cloud computing and big data support of internal production workplace communication.

Customer order specification and the reaction time of production process response to the customer order.

Digitized production controlling.

Production planning and scheduling based on the verification of relevant production databases and production management conditions.

Roll-out planning through augmented reality and digitized production planning ID competencies. 
Integration of relevant process attributes into the production planning, scheduling and organization.

Process constraints reaction time identified by IP-W (workplace) and IP-PF (process flow).

Mutual system connection standardization by human-cobot workplace, the efficiency of management actions and rules.

System constraints influence continuously process planning and realization given by human instructions in the digitized technologies.

Cybersecurity of feedback in the production planning stage and following the production process.

Requirements according to digitized process output (selected process KPI's).

Regarding the prerequisites listed in Table 6, the primary goal of production workplace standardization is to achieve optimal efficiency and effectiveness. Based on these assumptions, we must focus precisely on the formulation and definition of the process-standard content as well as the definition of core processes. According to the prerequisites of workplace process standard for the human-cobot ethical workplace, the following standardized processes were identified (Table 7):

- digitised production planning and scheduling in cooperation with augmented and virtual reality;

- big data availability;

- process monitoring and control through IP standardization;

- cloud computing within the MRP that continuously cooperates with other relevant SW tools for online production monitoring and evaluation;

- process flow structured database, actions, and feedback;

- e-platform schedule for human and cobot workplace tasks, jobs, competencies, and responsibilities;

- specification of production order by customer and verification online through the digitised production schedule;

- services and preventive maintenance in strong cooperation with online process monitoring and technology screening.

Tab. 7 - Production workplace standard - core processes specification criteria for the humancobot workplace. Source: own research

\begin{tabular}{|l|l|}
\hline $\begin{array}{l}\text { Core processes param- } \\
\text { eters for human-cobot } \\
\text { ethical workplace }\end{array}$ & PROCESS SPECIFICATION CRITERIA \\
\hline $\begin{array}{l}\text { Integration of planning } \\
\text { and scheduling process }\end{array}$ & $\begin{array}{l}\text { Production process order identification.ID input codes. Standardized } \\
\text { production schedule human-cobot job definition.Digitised produc- } \\
\text { tion flow schedule, including critical process elements connected to } \\
\text { required process output. }\end{array}$ \\
\hline
\end{tabular}




\begin{tabular}{|l|l|}
\hline $\begin{array}{l}\text { Digitised automation of } \\
\text { the process }\end{array}$ & $\begin{array}{l}\text { Manufacturing cell process organization. Hybrid cooperation of } \\
\text { human-cobot workplace process organization. Augmented reality } \\
\text { integrated into the production planning. Digitised technology map } \\
\text { and integrated technology availability for process performance. }\end{array}$ \\
\hline $\begin{array}{l}\text { Process performance } \\
\text { verification }\end{array}$ & $\begin{array}{l}\text { Production flow online monitoring and feedback. Digitised produc- } \\
\text { tion organization. Production scheduling based on selected KPI's } \\
\text { in the form of online process monitoring. IP human and cobot } \\
\text { identification by the jobs and production actions done. Digitised data } \\
\text { transfer past the production process. }\end{array}$ \\
\hline $\begin{array}{l}\text { Structured processes } \\
\text { and activities }\end{array}$ & $\begin{array}{l}\text { Production system parametrization. Qualification and competency } \\
\text { responsibilities of the human-cobot workplace. Flexible production } \\
\text { process organization. Administration-oriented data analytics on } \\
\text { production process flows. Standardized system for constraints and } \\
\text { breakdown monitoring. }\end{array}$ \\
\hline Maintenance & $\begin{array}{l}\text { Integrated concept of preventive and predictive services as well } \\
\text { as maintenance in strong cooperation with production planning. } \\
\text { Organization of e-maintenance actions by human-cobot workplace. } \\
\text { Process-oriented e-diagnostics realized by a human. Digitised e- } \\
\text { reports online during the manufacturing process. }\end{array}$ \\
\hline Customer satisfaction & $\begin{array}{l}\text { Digitised product and service reports for customers. Relevant cus- } \\
\text { tomer diagnostics outputs.Process quality feedback as background } \\
\text { for continuous improvement process. }\end{array}$ \\
\hline
\end{tabular}

\section{DISCUSSION}

The core interest in international research studies in the area of human-cobot workplace ethics has been concentrated on the phenomenon of the psychological ownership of human work and the technologically set work procedure of the cobot (Delgosha \& Hajiheydari, 2021). Given by human and digitally controlled technology (cobot), this new type of collaboration has a significant impact on productivity and efficiency. A research gap has emerges with regard to the orientation towards stable, ethical standardization in hybrid workplaces. In light of this, our research brings individual interviews with selected SMEs focused on the actual state of ethical workplace statements. Consequently, we tested the proposed catalogue of prerequisites (process standards by workplace). Our results opposed that of (Forquesato, 2016), thus this deviation shows the acute need to name critical factors in the area of ethics at the hybrid workplace, which represent basic elements of production workplace standards. Research studies show that the ethical site of production processes by human-cobot cooperation has a major impact on employee motivation and satisfaction along with productivity and company competitiveness. Many of the described problems have been connected with psychological disorders, a finding which was confirmed by our research as well as that of Cohen et al. (2019). The results of our study as well as other international investigations show an actual research gap with regard to the design of standardized process parameters as a possible approach to achieve a stable, ethical concern at the hybrid workplace. More enhanced collaboration among hybrid production workplaces leads to higher ethical satisfaction of employees (Pacaux-Lemoine et al., 2021). This connection can be 
seen to prepare the way for more profound research in the area of stable, ethical hybrid workplace parameters. Henceforward, we are working with SMEs on a more detailed description of the ethical workplace optimization criterion. These results should confirm or bring new knowledge regarding the process management of ethical human-cobot workplaces. Based on digitised technologies, the human can obtain a new space for radical innovation with the help of artificial intelligence; in collaboration with other authors the concentration on ethical site of job has become crucial. Again, the most important part of human-cobot cooperation ethics will be the active communication and cooperation between digitized systems and technologies (Fletscher \& Webb, 2017; Borangiu et al., 2013). We must emphasize that the knowledge and this first experience in hybrid workplace standardization represent the vital results of our research paper. In alliance with other colleagues in SMEs around the world, we are interested in further technical research in the following areas: compatibility of production planning and scheduling with ethical process management at workplaces, stable layout standardization, flexibility by job rotations and employees qualifications, technological and technical compliance of cobot requirements with human working conditions, and strict process management toward the elimination of process conflicts by the hybrid workplace.

\section{CONCLUSIONS}

The goal of this paper has been to devote attention to the significant influence of humancobot workplace ethics on the process standardization of collaborative workplaces. The results of this analysis and concept proposal should help improve industrial competitiveness among companies in the coming digital age. Cooperation with European universities will continue to define process models for predicting the ethical workplace. This will make it possible to design the flexibility of production directly utilizing this knowledge regarding effective workplace availability. With this work, the production manager is thus provided with the optimal tool for managing competitiveness directly at the shop floor level. The employee's satisfaction - and today also the cobot - represent essential interdependent factors in process performance.

The research results highlight the importance of human-cobot workplace ethics. In the following years, it will become most important to devote attention to the ethical stability of job connections. In the next few years, it will become most important to focus on the ethical stability of job connections in research oriented towards analysing ethical stability parameters related to the increase of digitally managed jobs in the workplace.

\section{References}

1. Al-Yacoub, A., Zhao,Y. C., Eaton, W., Goh, Y. M., \& Lohse, N. (2021): Improving humanrobot collaboration through Force/Torque-based learning for object manipulation. Robotics and Computer-Integrated Manufacturing, 69, 102111. https://doi.org/10.1016/j.rcim.2020.102111

2. Bendel, O. (2020). Co-robots from an Ethical perspective. Business Information Systems and Technology 4.0. Studies in Systems. Decision and Control. Berlin: Springer Verlag.

3. Borangiu, T., Thomas, A., Trentesaux, D. (2013). Service Orientation in Holonic and Multi-Agent Manufacturing. Berlin: Springer Verlag. 
4. Brahma,M., Tripathi,S. S., \& Sahay,A. (2021). Developing curriculum for Industry 4.0: digital workplaces. Higher Education, Skills and Work-Based Learning, 11, (1), 144-163. https://doi. org/10.1108/HESWBL-08-2019-0103

5. Brennan, C. (2018). Digital humanities. Digital methods. Digital history. Digital Outputs: History writing and the digital revolution. History Compass, 16 (10), https://doi.org/10.1111/ hic3.12492

6. Cardin, O. (2019). Classification of cyber-physical production systems applications: Proposition of an analysis framework. Computers in Industry, 104, 11-21, https://doi. org/10.1016/j.compind.2018.10.002

7. Cheng, Y., Sun, L., \& Tomizuka, M. (2021). Human-Aware Robot Task Planning Based on a Hierarchical Task Model. IEEE Robotics and Automation Letters, 6 (2), 1136-1143. https://doi. org/ 10.1109/LRA.2021.3056370

8. Cohen, Y., Shoval, S., \& Faccio, M. (2019). Strategic View on Cobot Deployment in Assembly 4.0 Systems. IFAC-PapersOnLine, 52 (13), 1519-1524, https://doi.org/10.1016/j. ifacol.2019.11.415

9. Delgosha, M. S, \& Hajiheydari, N. (2021). How do human users engage with consumer robots? A dual model of psychological ownership and trust to explain post-adoption behaviours. Computers in Human Behavior, 17, 10660. https://doi.org/10.1016/j.chb.2020.106660

10. Didomenico, P. (2019). Classification of cyber-physical production systems applications: Proposition of an analysis framework. Computers in Industry, 104, 11-21, https://doi. $\operatorname{org} / 10.1016 /$ j.compind.2018.10.002

11. Dornberger, R. (2018). Business Information Systems and Technology 4.0 - New Trends in the Age of Digital Change. Berlin: Springer Verlag.

12. Doyle, S., \& Senske, N. (2018). Digital provenance and material metadata: Attribution and coauthorship in the age of artificial intelligence. International Journal of Architectural Computing, 16 (4), 271-280. https://doi.org/10.1177/1478077118800887

13. Espada, A., \& Rosa, C. (2018). My Co-Worker is a Machine: a transgressive essay. Proceedings of the 5th Design Doctoral Conference. DDC'18. Transgression. IADE - Universidade Europeia.

14. Fisher, M., Mascardi, V., Rozier, K. Y., Schlingloff, B. H., Winikoff, M., \& Smith, N. Y. (2020). Towards a framework for certification of reliable autonomous systems. Auton Agents and MultiAgent Systems, 35 (8), 1-66.

15. Fletcher, S., \& Webb, P. (2017). Industrial Robot Ethics: The Challenges of Closer Human Collaboration in Future Manufacturing Systems. The World with Robots. Intelligent Systems Control and Automation Science and Engineering, 84 (1), 159-169. https://doi.org/10.1007/978-3319-46667-5_12

16. Forquesato, P. (2016). Social norms of work ethic and incentives in organizations. Journal of Economic Behavior \& Organization, 128 (1), 231-250. https://doi.org/10.1016/j.jebo.2016.05.012

17. Goleman, D. (2012). Emotional Intelligence - Why it can matter more than IQ. London: Bloomsbury.

18. Jocelyn, S., Vurlet-Vieney, G. L., \& Giraud, L. (2017). Experience Feedback on Implementing and Using Human-Robot Collaboration in the workplace. Proceedings of the Human Factors and Ergonomics Society, Annual Meeting, 62. 
19. Kopacek, P. (2018). Development Trends in Cost Oriented Production Automation. IFACPaper, 51 (30), 39-43.

20. Li, J., Tan, X., \& Li, J. (2018). Research on Dynamic Facility Layout Problem of Manufacturing Unit Considering Human Factors. Mathematical Problems in Engineering, 6040561. https://doi.org/10.1155/2018/6040561

21. Lin, P., Abney, K., \& Bekey, G. A. (2012). Robot Ethics - The ethical and social implications of robotics. Cambridge: MIT Press.

22. Mudrack, P. E., Bloodgood, J. M., \& Turnley, W. H. (2012). Some Ethical Implications of Individual Competitiveness. Journal of Business Ethics, 108, 347-359. https://doi.org/10.1007/ s10551-011-1094-4

23. Pacaux-Lemoine, M. P., \& Trentesaux, D. (2019). Ethical Risks of Human-Machine Symbiosis in Industry 4.0: Insights from the human-machine cooperation approach. IFAC-PapersOnLine, 52 (19), 19-24. https://doi.org/10.1016/j.ifacol.2019.12.077

24. Pacaux-Lemoine, M. P., Berdal, Q., \& Guérin, C. (2021). Designing human-system cooperation in industry 4.0 with cognitive work analysis: a first evaluation. Cognition, Technology \& Work, 2121. https://doi.org/10.1007/s10111-021-00667-y

25. Pollak, A., Paliga, M., Pulopulos, M. M., Kozusnik, B., \& Kozusznik, M. W. (2020). Stress in manual and autonomous modes of collaboration with a cobot. Computers in Human Behavior, 112, 106469. https://doi.org/10.1016/j.chb.2020.106469

26. Ramirez, E., \& LaBarge, S. (2018). Real moral problems in the use of virtual reality. Ethics and Information Technology, 20 (4), 249-263. https://doi.org/10.1007/s10676-018-9473-5

27. Romero, D., Stahre, J., \& Taisch, M. (2018). The Operator 4.0: Towards socially sustainable factories of the future. Computers \& Industrial Engineering, 139, 106128. https://doi. org/10.1016/j.cie.2019.106128

28. Salmi, T., Marstio, I., Malm, T., Laine, E. (2008). Man-Robot Cooperation - New Technologies and New Solutions. Conference Micro-Assembly Technologies and Applications, IFIP TC5 WG5.5 Fourth International Precision Assembly Seminar (IPAS'2008), Chamonix, https://doi.org/10-1007/978-0-387-77405-3_38

29. Sanda, M. A. (2020). Learning from Employee Perceptions of Human-Work and WorkOrganization in Digitized Production-Drilling Activitiy in Mines. Advances in Human Factors and Systems Interaction. AHFE 2019. Advances in Intelligent Systems and Computing, 959. https://doi.org/10.1007/978-3-030-20040-4_39

30. Sharma, S., Bawa, S., \& Lomash, H. (2018). Approaches in Cultural Computing: A Survey and Interference from Social Computing with Dynamics of Mind. Wireless Personal Communication, 103 (4), 2693-2713. https://doi.org/10.1007/s11277-018-5957-2

31. Shleifer, A. (2004). Does Competition Destroy Ethical Behavior? American Economic Review, 94 (2), 414-418. https://doi.org/10.1257/0002828041301498

32. Simoes, A. C., Soares, A. L., \& Barros, A. C. (2020). Factors influencing the intention of managers to adopt collaborative robots (cobots) in manufacturing organisations. Journal of Engineering and Technology Management, 57, 101574. https://doi.org/10.1016/j. jengtecman.2020.101574 
33. Steusloff, H. (2016). Humans are Back in the Loop! Would Production Process Related Ethics Support the Design? Operating and Standardization of Safe. Secure and Efficient HumanMachine-Collaboration? 4th International Conference on Future Internet of things and Cloud Workshops, 348-350.

34. Trentesaux, D., \& Karnouskos, S. (2019). Ethical Behaviour Aspects of Autonomous Intelligent Cyber-Physical Systems. Service-Oriented. Holonic and Multi-Agent Manufacturing Systems for Industry of the Future. SOHOMA. Studies in Computational Intelligence, 853, 55-71. https://doi.org/10.1007/978-3-030-27477-1_5

35. Trentesaux, D., \& Karnouskos, S. (2021). Engineering ethical behaviours in autonomous industrial cyber-physical human systems. Cognitive, Technology \& Work, 2021 https://doi. org/10.1007/s10111-020-00657-6

36. Vettier, L. (2019). Bio design, how to think production with the living? Philosophical Readings, 11 (1), 26-32.

37. Wildhaber, I. (2018). Artificial intelligence and robotics. The workplace. and workplace-law. Research Handbook on the Law of Artificial Intelligence. Cheltenham: Edward Elgar Publishing.

38. Yoo, M. J., \& Glardon, R. (2018). Manufacturing Operations Management. London: World Scientific Europe.

39. Zaatari, S., Marei, M., Weidong, L., \& Usman, Z. (2019). Cobot programming for collaborative industrial tasks: An overview. Robotics and Autonomous Systems, 116, 162-180. https://doi. org/10.1016/j.robot.2019.03.003

40. Zhao, D., \& Oh, J. (2020): Noticing Motion Patterns: A Temporal CNN With a Novel Convolution Operator for Human Trajectory Prediction. IEEE Robotics and Automation Letters, 6 (2), 628-634. https://doi.org/ 10.1109/LRA.2020.3047771

\section{Contact information}

prof. Ing. Felicita Chromjakova, PhD.

Tomas Bata University in Zlin

Faculty of Management and Economics

Department of Industrial Engineering and

Information Systems

Crech Republic

E-mail:chromjakova@utb.cz

ORCID: 0000-0002-5084-1153

prof. Dr.-Ing. Damien Trentesaux

LAMIH UMR CNRS 8201

Université Polytechnique Hauts-de-France

France

Email:damien.trentesaux@uphf.fr

ORCID: 0000-0003-2489-6203
Ing. Michael Adu Kwarteng, Ph.D.

Tomas Bata University in Zlin

Faculty of Management and Economics

Department of Management and Marketing

Czech Republic

E-mail:kwarteng@utb.cz.

ORCID: 0000-0002-6787-0401 